\title{
Cardiac oxygen supply is compromised during the night in hypertensive patients
}

\author{
Berend E. Westerhof • Johannes J. van Lieshout - Gianfranco Parati · \\ Gert A. van Montfrans • Ilja Guelen · Jos A. E. Spaan · Nico Westerhof • \\ John M. Karemaker • Willem Jan W. Bos
}

Received: 28 February 2011/ Accepted: 7 July 2011/Published online: 23 July 2011

(C) The Author(s) 2011. This article is published with open access at Springerlink.com

\begin{abstract}
The enhanced heart rate and blood pressure soon after awaking increases cardiac oxygen demand, and has been associated with the high incidence of acute myocardial infarction in the morning. The behavior of cardiac oxygen supply is unknown. We hypothesized that oxygen supply decreases in the morning and to that purpose investigated cardiac oxygen demand and oxygen supply at night and after awaking. We compared hypertensive to normotensive subjects and furthermore assessed whether pressures measured non-invasively and intraarterially give similar results. Aortic pressure was reconstructed from 24-h intra-brachial and simultaneously obtained non-invasive finger pressure in 14 hypertensives
\end{abstract}

B. E. Westerhof · I. Guelen

BMEYE, Amsterdam, The Netherlands

B. E. Westerhof · J. J. van Lieshout

Laboratory for Clinical Cardiovascular Physiology, Center

for Heart Failure Research, Academic Medical Center,

University of Amsterdam, Amsterdam, The Netherlands

J. J. van Lieshout $(\bowtie) \cdot$ G. A. van Montfrans

Special Medical Care, Department of Internal Medicine,

Academic Medical Centre, University of Amsterdam,

Room F7-205, PO Box 22700, 1100 DE Amsterdam, The

Netherlands

e-mail: j.j.vanlieshout@amc.uva.nl

G. Parati

II Cardiology Unit, S. Luca Hospital, University

of Milano-Bicocca and Istituto Auxologico Italiano,

Milan, Italy

J. A. E. Spaan

Department of Biomedical Engineering and Physics, Academic Medical Center, University of Amsterdam, Amsterdam, The Netherlands and 8 normotensives. Supply was assessed by Diastolic Time Fraction (DTF, ratio of diastolic and heart period), demand by Rate-Pressure Product (RPP, systolic pressure times heart rate, HR) and supply/demand ratio by $A_{\mathrm{dia}} / A_{\mathrm{sys}}$, with $A_{\text {dia }}$ and $A_{\text {sys }}$ diastolic and systolic areas under the aortic pressure curve. Hypertensives had lower supply by DTF and higher demand by RPP than normotensives during the night. DTF decreased and RPP increased in both groups after awaking. The DTF of hypertensives decreased less becoming similar to the DTF of normotensives in the morning; the RPP remained higher. $A_{\mathrm{dia}} / A_{\text {sys }}$ followed the pattern of DTF. Findings from invasively and non-invasively determined pressure were similar. The cardiac

\section{N. Westerhof}

Department of Physiology, Institute for Cardiovascular Research, ICaR-VU, VU University Medical Center, Amsterdam, The Netherlands

\section{N. Westerhof}

Department of Pulmonary Diseases, Institute for Cardiovascular Research, ICaR-VU, VU University Medical Center,

Amsterdam, The Netherlands

\section{J. M. Karemaker}

Department of Systems Physiology, Academic Medical Center, University of Amsterdam, Amsterdam, The Netherlands

W. J. W. Bos

Department of Internal Medicine, St Antonius Ziekenhuis, Nieuwegein, The Netherlands 
oxygen supply/demand ratio in hypertensive patients is lower than in normotensives at night. With a smaller nightday differences, the hypertensives' risk for cardiovascular events may be more evenly spread over the $24 \mathrm{~h}$. This information can be obtained noninvasively.

Keywords Aortic pressure - Cardiac oxygen demand . Noninvasive $\cdot$ Monitoring $\cdot$ Myocardial ischemia

\section{Introduction}

The increased risk of sudden cardiac death soon after awaking has stimulated the search for mechanisms responsible for this phenomenon [33, 34]. Apart from non-hemodynamic factors, attention has been mainly focused on the increase in heart rate and systolic blood pressure early in the morning, both indicators of cardiac oxygen demand. Obviously, patients with isolated systolic hypertension can be expected to have a higher demand. Since heart rate increases in the morning, the diastolic period, i.e., the time when an important part of subendocardial perfusion takes place, may be expected to decrease. Therefore, oxygen supply may decrease at the same time. Both cardiac oxygen supply and demand are relevant and changes in the ratio of supply and demand can be associated with morning excess of acute myocardial infarction [15, 28, 32-34].

We investigated whether changes in oxygen supply and demand from night to morning are different in hypertensives as compared to normotensives. A secondary goal was to investigate whether pressures measured non-invasively and intra-arterially give similar results. To this end we analyzed $24 \mathrm{~h}$ blood pressure and heart rate recordings using continuous and simultaneous intra-arterial brachial pressure and non-invasive finger arterial blood pressure tracings. Data were obtained in 14 hypertensive patients and in 8 healthy normotensive volunteers as part of a previous study [23]. Aortic pressure reconstructed from both brachial and finger pressures were analyzed to determine indices, which are accepted as parameters related to cardiac oxygen supply, cardiac oxygen demand, and the supply-demand ratio. We hypothesized that besides the well known increase in cardiac oxygen demand indices, additionally cardiac oxygen supply will decrease after rising.

\section{Methods}

\subsection{Subjects}

We studied 14 hypertensive patients (20-60 years; 10 men and 4 women) and 8 normotensive male volunteers (19-32 years) recorded for a blood pressure (BP) measurement validation study [23]. The hypertensives discontinued their medications 2 weeks prior to the measurements. All subjects gave written informed consent and the ethics committees approved the protocol [23].

\subsection{Measurements}

Invasive arterial pressure (IAP) was measured in the brachial artery of the non-dominant arm with the Oxford Medilog Mark II system and noninvasive arterial pressure (NAP) was obtained at a finger of the dominant arm using the Portapres device. For a detailed description we refer Imholz et al. [23]. Measurements were performed from 1 PM until 1 PM the next day. Apart from free in-hospital activities, all subjects performed the following activities at preset times: siesta (2:00-3:30 PM), cycling at $50 \mathrm{~W}$ (4:45-5:15 PM), sleep (10 PM-6 AM), and two walks outside the hospital (10:00-10:30 AM, 11:00-11:30 AM).

\subsection{Data analysis}

The blood pressure signals were A/D converted with a sampling rate of $100 \mathrm{~Hz}$, which is sufficient for signals with low frequency content such as arterial pressure. No moving averages or other smoothing techniques were used. Episodes with artefacts were rejected. Aortic pressure waves were reconstructed from invasive brachial and noninvasive finger artery pressures using two dedicated generalized transfer functions [5-7, 13, 20, 21, 27, 41, 43]. The transfer function compensates for the physiological transformation of pressure waves that travel towards the periphery. Data on validation of the generalized transfer functions between intra-arterially measured brachial pressure and aortic pressure [44], and between noninvasively obtained finger pressure and aortic pressure have been reported earlier [27]. Beat to beat values of systolic, mean and diastolic BP and heart rate (HR) were determined for the aortic pressures.

The following indices were derived from aortic pressure (Fig. 1):

- The diastolic time fraction (DTF, the ratio of duration of diastole and heart period) which reflects oxygen supply and is directly related to coronary blood flow if the coronary vasodilatory reserve is exhausted $[17,30$, 39].

- The rate-pressure product (RPP, systolic pressure times HR), which gauges cardiac oxygen demand [37, 42].

- The ratio of the diastolic area $\left(A_{\mathrm{dia}}\right)$ and systolic area $\left(A_{\text {sys }}\right)$ under the aortic pressure curve which is a measure of the supply-demand ratio [8, 9, 22, 38].

The cardiac oxygen demand parameter proposed by Rooke and Feigl [37] was also calculated. The formula is 


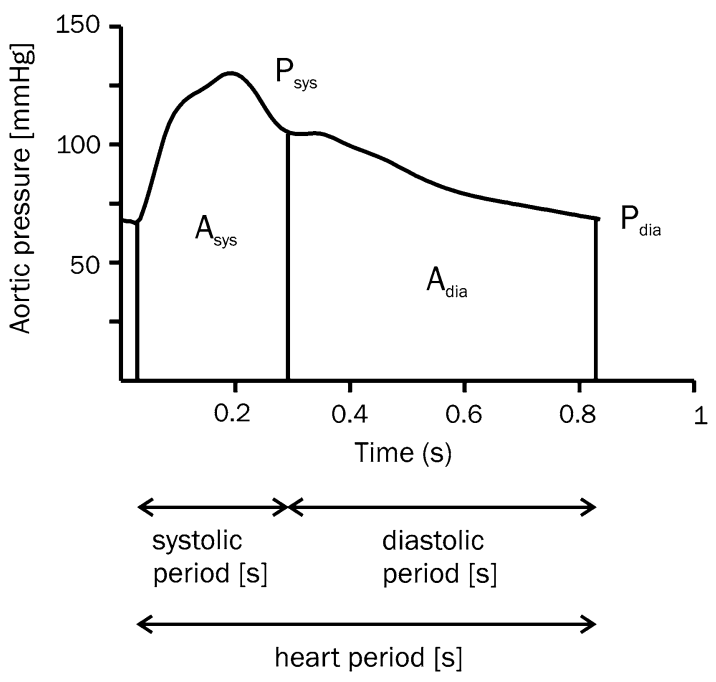

Fig. 1 Pressure derived indices of cardiac oxygen supply and demand. The ratio of the diastolic period to heart period (diastolic period plus systolic period), the diastolic time fraction (DTF) is measure of cardiac oxygen supply. The ratio of diastolic and systolic areas $(\mathrm{mmHg} \mathrm{s})$ under the reconstructed aortic pressure curve $\left(A_{\mathrm{dia}} /\right.$ $\left.A_{\text {sys }}\right)$ is a measure of supply-demand ratio. Heart rate $(60 /$ heart period) times maximal systolic pressure $P_{\text {sys }}$ gives rate pressure product (RPP) which is a measure of cardiac oxygen demand

$$
\begin{aligned}
\mathrm{MVO}_{2}= & K_{1}(\mathrm{SBP} * \mathrm{HR})+K_{2}(0.8 * \mathrm{SBP}+0.2 * \mathrm{DBP}) \\
& * \mathrm{HR} * \mathrm{SV} / \mathrm{BW}+1.43
\end{aligned}
$$

with $\mathrm{MVO}_{2}$ : left ventricular myocardial oxygen consumption ( $\left.\mathrm{ml} \mathrm{O}_{2} / \mathrm{min} / 100 \mathrm{~g}\right)$; SBP and DBP: systolic and diastolic blood pressure $(\mathrm{mmHg})$; $\mathrm{SV}$ : stroke volume $(\mathrm{ml})$ [40]; BW: body weight $(\mathrm{kg}) ; K_{1}: 4.08 \times 10^{-4}$ and $K_{2}$ : $3.25 \times 10^{-4}$.

Results are obtained from intra-arterially determined brachial pressure and from noninvasively measured pressure for comparison. Thirty-minute averages were calculated for all indices. The effect of morning rising was evaluated by comparing 10 30-min averages before (12:30-05:00, night) and after rising (08:30-13:00, morning). Although awaking was at 06:00 according to the protocol, some uncertainty exists whether or not all patients awoke/rose at exactly that time. Therefore, the period between 05:30 and 08:00 was not included in the analysis, comparable to practice in the analysis of the morning blood pressure surge [24].

Results were expressed as mean $\pm \mathrm{SD}$ in tables and as mean $\pm \mathrm{SE}$ in figures. Night vs. morning values from hypertensives vs. normotensives were compared by twoway ANOVA. The Tukey test was used for post hoc multiple comparisons if significant group and/or interaction effects were detected. Indices from NAP and IAP were compared with Bland and Altman analysis [3].

\section{Results}

Diurnal variations in aortic blood pressure, derived from intrabrachial pressure, (systolic, diastolic, and mean pressure) and heart rate are depicted in Fig. 2, and the indices calculated from heart rate and aortic pressure are presented in Fig. 3. The comparison of indices from NAP and IAP is shown in Fig. 4.

During the night, hypertensive patients had higher systolic, mean and diastolic BP and HR than normotensive subjects (Table 1). Values of the oxygen supply index DTF as well as the supply-demand ratio $\left(A_{\mathrm{dia}} / A_{\text {sys }}\right)$ were lower, whereas values of the oxygen demand index RPP were higher.

In the morning BP and HR as well as RPP increased in both groups, while DTF and $A_{\text {dia }} / A_{\text {sys }}$ decreased. BP, HR and RPP remained higher in the hypertensive group, DTF and $A_{\mathrm{dia}} / A_{\text {sys }}$ became similar for both groups.

In Table 2 the day-night differences are given. The change in diastolic pressure and RPP was the same for both groups, however, the other pressures and HR (Table 2; Fig. 2), and DTF and $A_{\text {dia }} / A_{\text {sys }}$ changed less in the hypertensive patients (Table 2; Fig. 3). Calculation of oxygen demand using the formula published by Rooke and Feigl [37] gave results very similar to the RPP (normotensives increasing from $3.53 \pm 0.07$ to $5.54 \pm 0.43$ after awaking and hypertensives from $4.77 \pm 0.19$ to $6.44 \pm 0.24 \mathrm{ml} \mathrm{O}_{2} /$ $\min / 100 \mathrm{~g}$.

\section{Discussion}

This study determined the diurnal variations in BP, HR and in indices of cardiac oxygen supply and oxygen demand in hypertensive patients and normotensive subjects.

The major findings are the following: first, both in normotensive and in hypertensive subjects, an increase in cardiac oxygen demand soon after awaking was accompanied by a reduction in cardiac oxygen supply.

Second, hypertensives differed from normotensives, having a higher cardiac oxygen demand and a lower supply during night-time. Third, their diurnal variations in both cardiac oxygen supply and the supply-demand ratio are smaller to the effect that these values approach the levels of normotensive subjects during the morning. This suggests a reduced adaptive circulatory capacity in hypertensive subjects with a less evident worsening in the morning.

Fourth, similar results were obtained from noninvasive and intra-arterial brachial pressure recordings, implying that myocardial oxygen supply and demand indices can be determined noninvasively making it applicable in larger populations [11]. 
Fig. 2 Diurnal blood pressure and heart rate in normotensive and hypertensive subjects. Data show mean and SE. Dotted vertical lines identify night and morning periods; bars indicate activities (siesta, cycling, sleeping and two walks (see pressure and heart rate in the morning are less pronounced in the hypertensives Sect. 2). The changes in blood
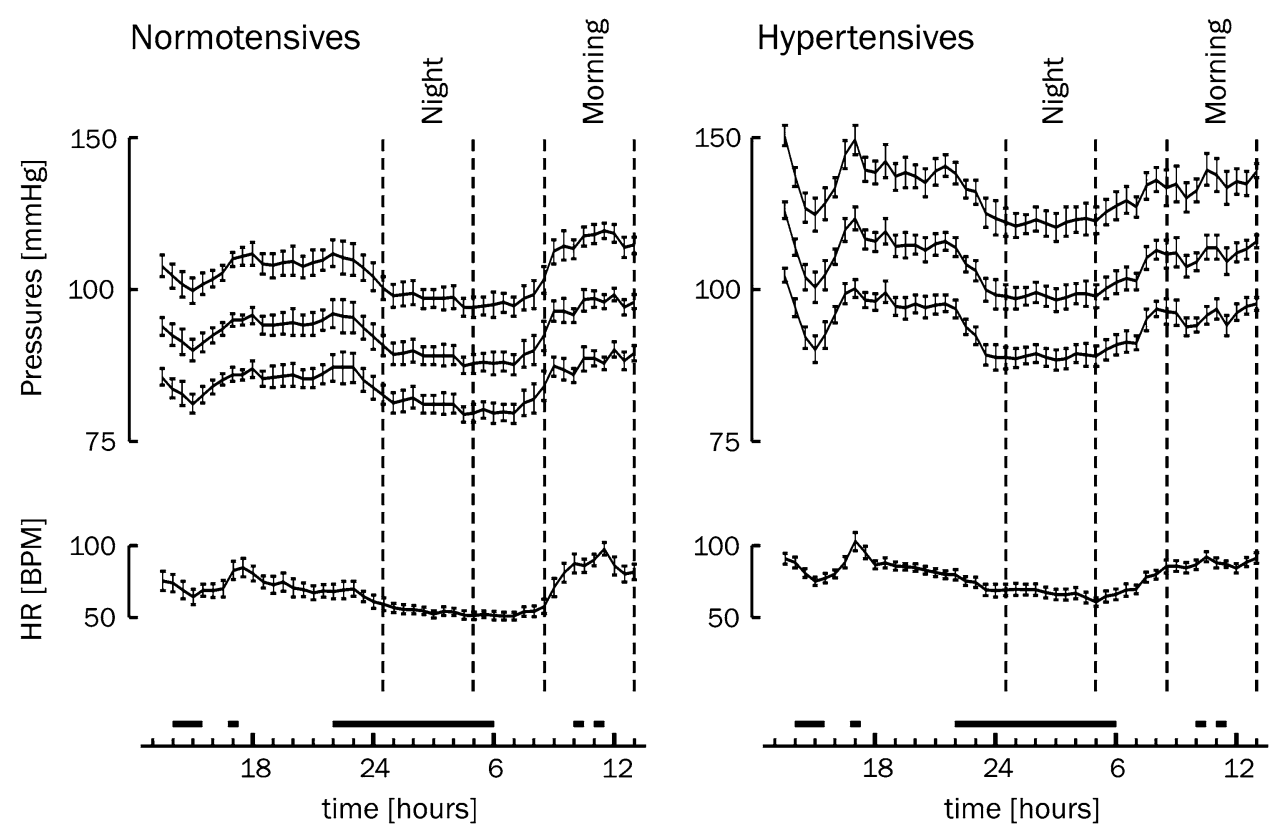

Fig. 3 Indices of cardiac oxygen supply and demand in normotensive and hypertensive subjects. DTF: diastolic time fraction, index of cardiac oxygen supply); $A_{\mathrm{dia}} / A_{\text {sys }}$ : oxygen supply-demand ratio; RPP: rate pressure product, index of cardiac oxygen demand. The slope of indices change in the morning is less pronounced in the hypertensive than in the normotensive group

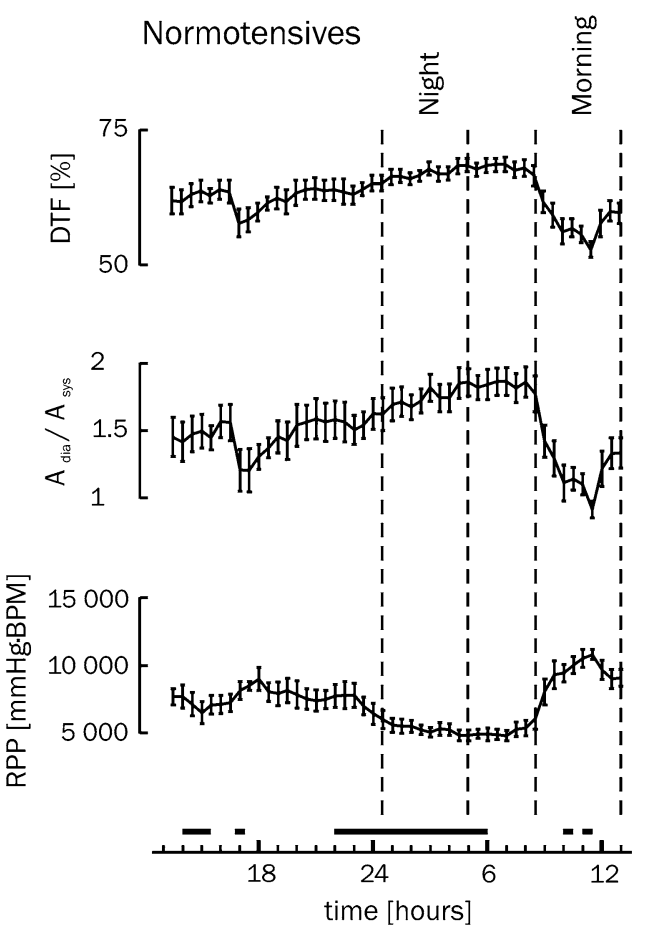

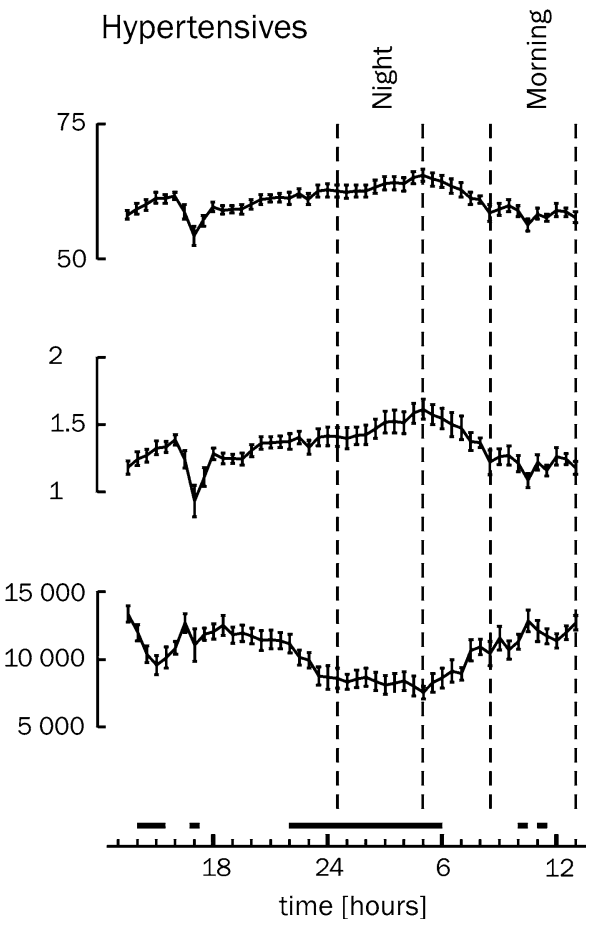

\subsection{Methodological considerations}

To obtain supply and demand indices aortic pressure is required, since that is the pressure loading the heart, and providing coronary perfusion [45, 46]. Oxygen supplydemand indices were therefore derived from aortic pressure waves, reconstructed from both invasive brachial artery pressure and from non-invasive finger arterial pressure recordings, using appropriate transfer functions [5, 20, 41, $43,44]$. Transfer functions compensate for the transformation of pressure waves while they travel towards the periphery. The transfer functions mainly correct for the amplification of the systolic pressure [5, 20, 41, 43] and therefore above all affect calculation of RPP and $A_{\text {sys. }}$. Generalized waveform filters in the upper limb show little inter-individual variation at low frequencies [6, 7, 13, 41], which is of importance for the calculation of mean and diastolic pressure, and thus for calculation of DTF and $A_{\text {dia. }}$. Therefore, inaccuracies introduced by the use of a generalized transfer function should do not have a major effect 
Fig. 4 Cardiac oxygen indices from non-invasive vs. invasive arterial pressure. Noninvasively (NAP) and invasively (IAP) derived cardiac oxygen indices in Bland and Altman fashion. Please note that the horizontal and vertical axes have the same scale so that the differences can be easily assessed relative to the average values. DTF: diastolic time fraction; $A_{\mathrm{dia}} / A_{\text {sys }}$ : ratio of diastolic and systolic areas; RPP: rate pressure product
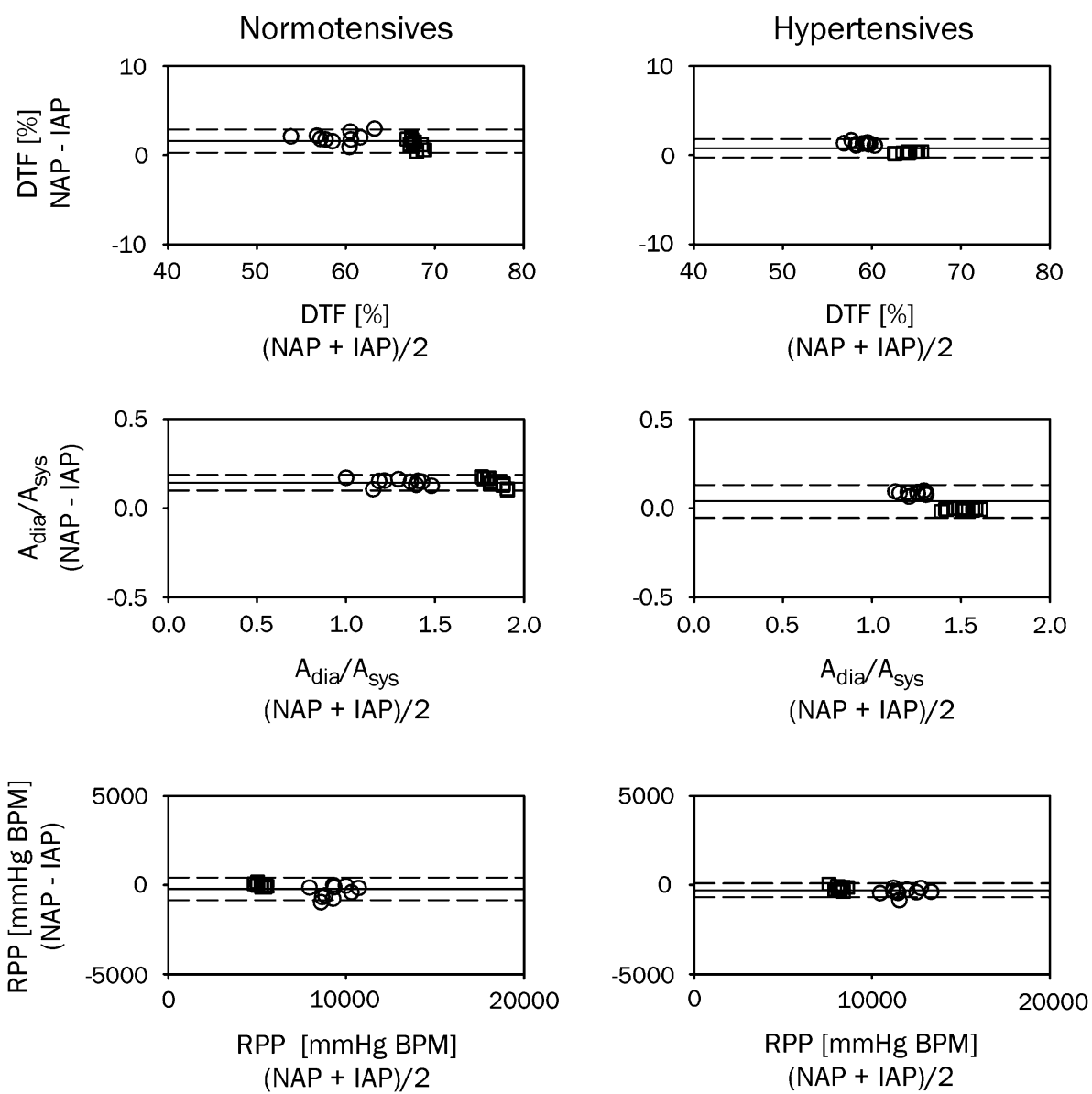

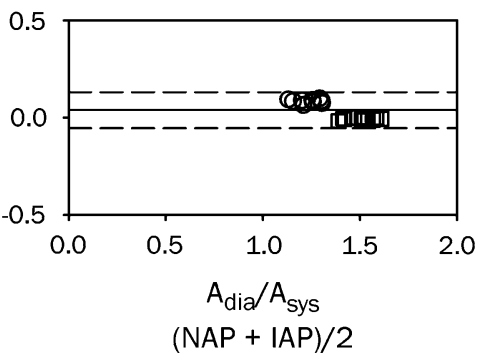

Hypertensives

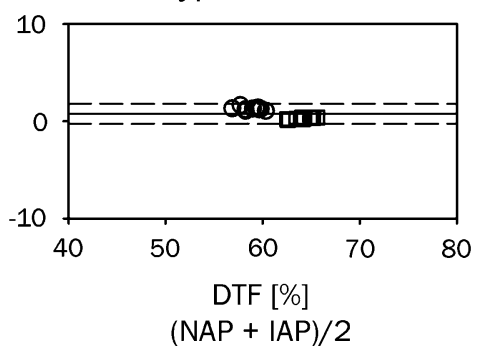

$(N A P+I A P) / 2$
Table 1 Hemodynamic variables and derived cardiac oxygen supply and demand indices

* indicates a significant difference $(P<0.05)$ between morning and night, ${ }^{\dagger}$ indicates a significant difference $(P<0.05)$ between hypertensives and normotensives

Night averages (top) and morning averages (bottom) for normotensive (left) and hypertensive (right) subjects. $P_{\text {sys }}, P_{\text {dia }}$, and $P_{\text {mean }}$ systolic, diastolic, and mean aortic pressure; $H R$ heart rate, $D T F$ diastolic time fraction, $R P P$ rate pressure product, $A_{\mathrm{dia}} / A_{\text {sys }}$ ratio of diastolic and systolic areas (mmHg s), respectively, under the aortic pressure curve reconstructed from intrabrachial pressure

\begin{tabular}{|c|c|c|c|c|c|c|c|}
\hline \multirow[t]{2}{*}{ Night $(0: 30-5: 00)$} & \multicolumn{3}{|c|}{ Normotensives } & \multicolumn{3}{|c|}{ Hypertensives } & \multirow{2}{*}{$\begin{array}{l}\text { Hypertensives } \\
\text { vs. } \\
\text { normotensives }\end{array}$} \\
\hline & Mean & & & Mean & & & \\
\hline$P_{\text {sys }}(\mathrm{mmHg})$ & 97 & \multicolumn{2}{|c|}{2} & 123 & \multicolumn{2}{|c|}{1} & $\dagger$ \\
\hline$P_{\mathrm{dia}}(\mathrm{mmHg})$ & 61 & \multicolumn{2}{|c|}{2} & 78 & \multicolumn{2}{|c|}{1} & $\dagger$ \\
\hline$P_{\text {mean }}(\mathrm{mmHg})$ & 78 & \multicolumn{2}{|c|}{2} & 98 & \multicolumn{2}{|c|}{1} & $\dagger$ \\
\hline HR (BPM) & 54 & \multicolumn{2}{|c|}{2} & 67 & \multicolumn{2}{|c|}{3} & $\dagger$ \\
\hline DTF $(\%)$ & 67.2 & \multicolumn{2}{|c|}{0.9} & 63.8 & \multicolumn{2}{|c|}{1.1} & $\dagger$ \\
\hline$A_{\mathrm{dia}} / A_{\mathrm{sys}}$ & 1.76 & \multicolumn{2}{|c|}{0.07} & 1.50 & \multicolumn{2}{|c|}{0.07} & $\dagger$ \\
\hline RPP (mmHg BPM) & 5200 & \multicolumn{2}{|c|}{280} & 8260 & \multicolumn{2}{|c|}{320} & $\dagger$ \\
\hline Morning (8:30-13:00) & Mean & SD & $\begin{array}{l}\text { Morning vs. } \\
\text { night }\end{array}$ & Mean & SD & $\begin{array}{l}\text { Morning vs. } \\
\text { night }\end{array}$ & $\begin{array}{l}\text { Hypertensives } \\
\text { vs. } \\
\text { normotensives }\end{array}$ \\
\hline$P_{\text {sys }}(\mathrm{mmHg})$ & 116 & 2 & $*$ & 136 & 3 & $*$ & $\dagger$ \\
\hline$P_{\text {dia }}(\mathrm{mmHg})$ & 77 & 3 & * & 92 & 3 & $*$ & $\dagger$ \\
\hline$P_{\text {mean }}(\mathrm{mmHg})$ & 95 & 2 & * & 112 & 3 & $*$ & $\dagger$ \\
\hline HR (BPM) & 84 & 7 & $*$ & 89 & 5 & $*$ & $\dagger$ \\
\hline DTF $(\%)$ & 58.1 & 2.7 & $*$ & 58.3 & 1.1 & $*$ & NS \\
\hline$A_{\text {dia }} / A_{\text {sys }}$ & 1.22 & 0.15 & $*$ & 1.20 & 0.06 & $*$ & NS \\
\hline$\underline{\mathrm{RPP}}(\mathrm{mmHg} \mathrm{BPM})$ & 9510 & 800 & $*$ & 12000 & 840 & $*$ & $\dagger$ \\
\hline
\end{tabular}


Table 2 Day-night differences

\begin{tabular}{|c|c|c|c|c|c|}
\hline \multirow[t]{2}{*}{ Day-night } & \multicolumn{2}{|c|}{ Normotensives } & \multicolumn{2}{|c|}{ Hypertensives } & \multirow{2}{*}{$\begin{array}{l}\text { Hypertensives vs. } \\
\text { normotensives }\end{array}$} \\
\hline & Mean & $\mathrm{SD}$ & Mean & SD & \\
\hline$P_{\text {sys }}(\mathrm{mmHg})$ & 19 & 3 & 13 & 3 & $\dagger$ \\
\hline$P_{\mathrm{dia}}(\mathrm{mmHg})$ & 15 & 5 & 14 & 3 & NS \\
\hline$P_{\text {mean }}(\mathrm{mmHg})$ & 18 & 3 & 14 & 3 & $\dagger$ \\
\hline HR (BPM) & 31 & 8 & 23 & 7 & $\dagger$ \\
\hline DTF $(\%)$ & -9.1 & 2.7 & -5.5 & 1.9 & $\dagger$ \\
\hline$A_{\text {dia }} / A_{\text {sys }}$ & -0.54 & 0.15 & -0.30 & 0.11 & $\dagger$ \\
\hline RPP (mmHg BPM) & 4310 & 880 & 3740 & 1040 & NS \\
\hline
\end{tabular}

$\dagger$ indicates a significant difference $(P<0.05)$ between hypertensives and normotensives

$P_{\text {sys }}, P_{\text {dia }}$, and $P_{\text {mean }}$ systolic, diastolic, and mean aortic pressure; $H R$ heart rate, $D T F$ diastolic time fraction, $R P P$ rate pressure product; $A_{\text {dia }} / A_{\text {sys }}$ ratio of diastolic and systolic areas $(\mathrm{mmHg} \mathrm{s})$, respectively, under the aortic pressure curve reconstructed from intra-brachial pressure

on the estimates of cardiac oxygen supply. Please note that the cardiac oxygen demand can be readily approximated from measurement of systolic blood pressure and heart rate, for instance obtained with an oscillometric method. For supply parameters DTF and $A_{\text {dia }}$ the analysis of the waveform is required. The need for more advanced methods might in part explain the fact that in the literature more attention has been paid to changes in demand parameters than to changes in supply parameters. Finally, left ventricular diastolic pressure was not taken into account [8]. This may introduce an error in patients with increased left ventricular filling pressures [12]. If the left ventricular diastolic pressure would have been taken into account, the supply indices would decrease. Speculatively, this would have a larger effect in the hypertensives, resulting in less favorable numbers for this group [10].

Cardiac oxygen supply and oxygen demand were derived from aortic pressure in normotensive and hypertensive subjects. Continuous ambulatory coronary flow measurement, as a more direct measure of supply, to validate the reduction in coronary perfusion in patients with coronary heart disease is not yet feasible. Simultaneous oxygen supply-demand indices from continuous blood pressure together with ST-segment changes in patients with coronary heart disease, might, in part, answer the question whether myocardial ischemia correlates best with changes in oxygen supply vs. demand indices. This issue should be explored in studies aimed at elucidating the mechanisms behind our findings. Our results show clear differences between normotensive and hypertensive subjects in the diurnal hemodynamic patters. We acknowledge the limited size of the study population preventing us from generalizing the observed differences between the subject groups.

\subsection{Diurnal hemodynamic variations}

Major changes in oxygen supply-demand indices occur after rising, i.e., at the time when the peak in ischemic events is usually observed $[14,47]$. In this study the diurnal variation in the cardiac oxygen supply indices and in the $A_{\text {dia }} / A_{\text {sys }}$ ratio was smaller in hypertensive than in normotensive subjects, a phenomenon not described before. This does not necessarily indicate a reduced risk in hypertensives in the morning, because the smaller difference between night and morning values of these indices was largely due to higher values at night, only becoming similar to the values found in the normotensive subjects in the morning. Indeed, hypertensive subjects appear to be at risk for ischemic events due to larger oxygen demand [19, 25] during night as well as in the morning. On the other hand, the reduced oxygen supply at night in hypertensives may play a hitherto overlooked role in the occurrence of nocturnal ischemia [4, 35, 36].

Subendocardial perfusion is hampered if the $A_{\mathrm{dia}} / A_{\text {sys }}$ ratio falls below $0.4-0.6[2,22]$. The ratios observed in this study, in which no strenuous exercise was performed, remained well above this limit in all subjects of both groups. However, this limit is not fixed but may approach the value corresponding to subendocardial ischemia under circumstances where the vasodilatory reserve is exhausted, e.g., in case of coronary artery stenosis. Thus the magnitude of the observed changes in $A_{\mathrm{dia}} / A_{\text {sys }}$ ratio per se does not reflect early morning myocardial ischemia in healthy subjects, but may explain occurrence of coronary ischemia in those subjects who suffer from coronary artery disease. In hypertensive subjects [29] as well as in myocardial hypertrophy [18], coronary flow reserve is reduced, rendering oxygen supply indices better indicators of subendocardial ischemia in hypertensive than in normotensive subjects. In these patients the lower limit of the ratio may be higher than 0.6. Although cardiac oxygen indices may help in giving physiological insight; it is unlikely that they can serve as a diagnostic tool in an individual patient [21].

It should be recalled, that at the time of rise, nonhemodynamic factors as increased sympathetic activity and cortisol levels as well as platelet aggregability as 
independent risk factors [33] may contribute to morning increase in cardiovascular events rate through different mechanisms.

\subsection{Cardiac oxygen supply}

As soon as coronary vasodilatory reserve is exhausted, e.g., when a coronary stenosis is present, subendocardial and mid-myocardial perfusion become directly dependent on diastolic pressure and time [8, 9, 17, 22, 30]. Traditionally, reduced supply is associated with coronary vasospasm or atherosclerosis [33]. The present study demonstrates that hemodynamic changes may equally affect an index of cardiac oxygen supply (DTF and duration of diastole) in the morning.

A reduction in DTF can be attributed to an increase in HR primarily through the associated shortening of diastolic time. In healthy subjects a decrease in perfusion pressure or diastolic time is compensated for by coronary vasodilation [22]. This makes the decrease in the oxygen supply index of importance mainly in patients with limited vasodilatory capacity as in coronary stenosis. To the best of our knowledge this supply index, in contrast to the demand indices, has never been associated with cardiac ischemic events in the morning [14]. Pepine mentions the beneficial effects of beta-blockers on cardiac oxygen supply because of the prolongation of diastolic time, but not in relation to circadian changes in cardiac oxygen supply [33].

\subsection{Cardiac oxygen demand}

Diurnal variations in the balance between cardiac oxygen supply and demand have traditionally been attributed to changes in oxygen demand related to physical activity [26, 32-34]. The close correlation between an increase in HR and subsequent development of coronary ischemia is considered to reflect this increase in oxygen demand $[1,16]$. The observed increase in RPP after rising, as the result of an increase in both systolic blood pressure and heart rate, is in agreement with the hypothesis that the increased incidence of ischemic events in the morning may be related to an increase in cardiac oxygen demand. The oxygen demand as predicted by the more refined method of Rooke and Feigl [37] gave trends very similar to the RPP in our study, thus supporting the consistency of the information carried by RPP use.

Guelen et al. investigated the relation between cardiac oxygen supply and demand and aortic stiffness [21] and recently, Namasivayam et al. [31] described the effect of wave reflection on cardiac oxygen demand. Given the association that was found in the latter study between prolonged ejection time, and thus perhaps a shorter diastolic time fraction, it would be of interest to investigate the effect of wave reflection on cardiac oxygen supply as well.

\section{Conclusion}

Our study offers information on the assessment of the myocardial oxygen supply and demand. Traditionally an increased cardiac oxygen demand has been considered as the factor reducing the oxygen supply-demand balance. However, we observed that the balance also changes negatively by a reduction of the oxygen supply. The smaller morning increase in HR in our hypertensive group limits a further morning deterioration of oxygen indices, their values being already unfavorable at night. This suggests that, with the smaller night-day differences in supplydemand indices, the cardiovascular risk in hypertensives is more evenly spread over the day and night than in normotensives.

The indices derived from intra-arterial and from finger pressure give comparable results, implying that noninvasive finger pressure suffices to obtain this information.

Further studies addressing cardiac death rate during the night and awakening in normotensives vs. hypertensives are now needed to assess the clinical relevance of our findings.

Disclosure Berend E. Westerhof and Ilja Guelen are employees of BMEYE and own shares of BMEYE.

Conflicts of interest Johannes J van Lieshout, Gianfranco Parati, Gert A van Montfrans, Jos AE Spaan, Nico Westerhof, John M Karemaker and Willem Jan W Bos have no conflict of interest to declare.

Open Access This article is distributed under the terms of the Creative Commons Attribution Noncommercial License which permits any noncommercial use, distribution, and reproduction in any medium, provided the original author(s) and source are credited.

\section{References}

1. Andrews TC, Fenton T, Toyosaki N, Glasser SP, Young PM, MacCallum G, Gibson RS, Shook TL, Stone PH (1993) Subsets of ambulatory myocardial ischemia based on heart rate activity. Circadian distribution and response to anti-ischemic medication. The Angina and Silent Ischemia Study Group (ASIS). Circulation 88:92-100

2. Barnard RJ, MacAlpin R, Kattus AA, Buckberg GD (1973) Ischemic response to sudden strenuous exercise in healthy men. Circulation 48:936-942

3. Bland JM, Altman DG (1986) Statistical methods for assessing agreement between two methods of clinical measurement. Lancet $1: 307-310$

4. Bonsignore MR, Smirne S, Marrone O, Insalaco G, Salvaggio A, Bonsignore G (1999) Myocardial ischemia during sleep. Sleep Med Rev 3:241-255 
5. Bos WJW, Van Goudoever J, Van Montfrans GA, Van den Meiracker AH, Wesseling KH (1996) Reconstruction of brachial artery pressure from noninvasive finger pressure measurements. Circulation 94:1870-1875

6. Bos WJW, Zietse R, Wesseling KH, Westerhof N (1999) Effects of arteriovenous fistulas on cardiac oxygen supply and demand. Kidney Int 55:2049-2053

7. Bos WJW, Bruin S, Van Olden RW, Keur I, Wesseling KH, Westerhof N, Krediet RT, Arisz LA (2000) Cardiac and hemodynamic effects of hemodialysis and ultrafiltration. Am J Kidney Dis $35: 819-826$

8. Buckberg GD, Fixler DE, Archie JP, Hoffman JI (1972) Experimental subendocardial ischemia in dogs with normal coronary arteries. Circ Res 30:67-81

9. Buckberg GD, Fixler DE, Archie JP, Henney RP, Hoffman JI (1975) Variable effects of heart rate on phasic and regional left ventricular muscle blood flow in anaesthetized dogs. Cardiovasc Res 9:1-11

10. Chemla D, Nitenberg A (2008) Potential association between aortic stiffness, diastolic/systolic pressure time index and the balance between cardiac oxygen supply and demand: a word of caution. J Hypertens 26:2250-2251

11. Chemla D, Nitenberg A, Teboul JL, Richard C, Monnet X, le Clesiau H, Valensi P, Brahimi M (2008) Subendocardial viability ratio estimated by arterial tonometry: a critical evaluation in elderly hypertensive patients with increased aortic stiffness. Clin Exp Pharmacol Physiol 35:909-915

12. Chemla D, Nitenberg A, Teboul JL, Richard C, Monnet X, le CH, Valensi P, Brahimi M (2009) Subendocardial viability index is related to the diastolic/systolic time ratio and left ventricular filling pressure, not to aortic pressure: an invasive study in resting humans. Clin Exp Pharmacol Physiol 36:413-418

13. Chen $\mathrm{CH}$, Nevo E, Fetics B, Pak PH, Yin FC, Maughan WL, Kass DA (1997) Estimation of central aortic pressure waveform by mathematical transformation of radial tonometry pressure. Validation of generalized transfer function. Circulation 95:1827-1836

14. Cohen MC, Rohtla KM, Lavery CE, Muller JE, Mittleman MA (1997) Meta-analysis of the morning excess of acute myocardial infarction and sudden cardiac death. Am J Cardiol 79:1512-1516

15. Deedwania PC (1993) Increased demand versus reduced supply and the circadian variations in ambulatory myocardial ischemia. Therapeutic implications. Circulation 88:328-331

16. Deedwania PC, Nelson JR (1990) Pathophysiology of silent myocardial ischemia during daily life. Hemodynamic evaluation by simultaneous electrocardiographic and blood pressure monitoring. Circulation 82:1296-1304

17. Fokkema DS, VanTeeffelen JW, Dekker S, Vergroesen I, Reitsma JB, Spaan JA (2005) Diastolic time fraction as a determinant of subendocardial perfusion. Am J Physiol Heart Circ Physiol 288:H2450-H2456

18. Galderisi M, De Simone G, Cicala S, De Simone L, D'Errico A, Caso P, de Divitiis O (2003) Coronary flow reserve in hypertensive patients with appropriate or inappropriate left ventricular mass. J Hypertens 21:2183-2188

19. Gillman MW, Kannel WB, Belanger A, D'Agostino RB (1993) Influence of heart rate on mortality among persons with hypertension: the Framingham Study. Am Heart J 125:1148-1154

20. Gizdulich P, Prentza A, Wesseling KH (1997) Models of brachial to finger pulse wave distortion and pressure decrement. Cardiovasc Res 33:698-705

21. Guelen I, Mattace-Raso FU, van Popele NM, Westerhof BE, Hofman A, Witteman JC, Bos WJ (2008) Aortic stiffness and the balance between cardiac oxygen supply and demand: the Rotterdam Study. J Hypertens 26:1237-1243
22. Hoffman JI, Buckberg GD (1978) The myocardial supply: demand ratio-a critical review. Am J Cardiol 41:327-332

23. Imholz BPM, Langewouters GJ, Van Montfrans GA, Parati G, Van Goudoever J, Wesseling KH, Wieling W, Mancia G (1993) Feasibility of ambulatory, continuous 24-hour finger arterial pressure recording. Hypertension 21:65-73

24. Kario K, Pickering TG, Umeda Y, Hoshide S, Hoshide Y, Morinari M, Murata M, Kuroda T, Schwartz JE, Shimada K (2003) Morning surge in blood pressure as a predictor of silent and clinical cerebrovascular disease in elderly hypertensives: a prospective study. Circulation 107:1401-1406

25. Kozakova M, Galetta F, Gregorini L, Bigalli G, Franzoni F, Giusti C, Palombo C (2000) Coronary vasodilator capacity and epicardial vessel remodeling in physiological and hypertensive hypertrophy. Hypertension 36:343-349

26. Krantz DS, Kop WJ, Gabbay FH, Rozanski A, Barnard M, Klein J, Pardo Y, Gottdiener JS (1996) Circadian variation of ambulatory myocardial ischemia. Triggering by daily activities and evidence for an endogenous circadian component. Circulation 93:1364-1371

27. Lasance HAJ, Wesseling KH, Ascoop CA (1976) Peripheral pulse contour analysis in determining stroke volume. Progress Report Inst Med Phys 5:59-62

28. Li JJ (2003) Circadian variation in myocardial ischemia: the possible mechanisms involving in this phenomenon. Med Hypotheses 61:240-243

29. Marcus ML, Mueller TM, Eastham CL (1981) Effects of shortand long-term left ventricular hypertrophy on coronary circulation. Am J Physiol 241:H358-H362

30. Merkus D, Kajiya F, Vink H, Vergroesen I, Dankelman J, Goto M, Spaan JA (1999) Prolonged diastolic time fraction protects myocardial perfusion when coronary blood flow is reduced. Circulation 100:75-81

31. Namasivayam M, Adji A, O'Rourke MF (2011) Influence of aortic pressure wave components determined noninvasively on myocardial oxygen demand in men and women. Hypertension 57:193-200

32. Parker JD, Testa MA, Jimenez AH, Tofler GH, Muller JE, Parker JO, Stone PH (1994) Morning increase in ambulatory ischemia in patients with stable coronary artery disease. Importance of physical activity and increased cardiac demand. Circulation 89:604-614

33. Pepine CJ (1991) Circadian variations in myocardial ischemia. Implications for management. JAMA 265:386-390

34. Pepine CJ (1991) Therapeutic implications of circadian variations in myocardial ischemia and related physiologic functions. Am J Hypertens 4:442S-448S

35. Peters RW, Zoble RG, Brooks MM (2002) Onset of acute myocardial infarction during sleep. Clin Cardiol 25:237-241

36. Quyyumi AA, Wright CA, Mockus LJ, Fox KM (1984) Mechanisms of nocturnal angina pectoris: importance of increased myocardial oxygen demand in patients with severe coronary artery disease. Lancet 1:1207-1209

37. Rooke GA, Feigl EO (1982) Work as a correlate of canine left ventricular oxygen consumption, and the problem of catecholamine oxygen wasting. Circ Res 50:273-286

38. Sarnoff SJ, Braunwald E, Welch GH, Case RB, Stainsby WN, Macruz R (1958) Hemodynamic determinants of oxygen consumption of the heart with special reference to the tension-time index. Am J Physiol 192:148-156

39. van den Wijngaard JP, Kolyva C, Siebes M, Dankelman J, van Gemert MJ, Piek JJ, Spaan JA (2008) Model prediction of subendocardial perfusion of the coronary circulation in the presence of an epicardial coronary artery stenosis. Med Biol Eng Comput $46: 421-432$ 
40. Wesseling KH, Jansen JRC, Settels JJ, Schreuder JJ (1993) Computation of aortic flow from pressure in humans using a nonlinear, three-element model. J Appl Physiol 74:2566-2573

41. Westerhof BE, Guelen I, Parati G, Groppelli A, Van Montfrans G, Wieling W, Wesseling KH, Bos WJW (2002) Variable day/night bias in 24-h non-invasive finger pressure against intrabrachial artery pressure is removed by waveform filtering and level correction. J Hypertens 20:1981-1986

42. Westerhof N, Stergiopulos N, Noble MI (2005) Snapshots of hemodynamics. An aid for clinical research and graduate education

43. Westerhof BE, Guelen I, Stok WJ, Wesseling KH, Spaan JA, Westerhof N, Bos WJ, Stergiopulos N (2007) Arterial pressure transfer characteristics: effects of travel time. Am J Physiol Heart Circ Physiol 292:H800-H807

44. Westerhof BE, Guelen I, Stok WJ, Lasance HA, Ascoop CA, Wesseling KH, Westerhof N, Bos WJ, Stergiopulos N, Spaan JA
(2008) Individualization of transfer function in estimation of central aortic pressure from the peripheral pulse is not required in patients at rest. J Appl Physiol 105(6):1858-1863

45. Wilkinson IB, McEniery CM, Cockcroft JR (2006) Atenolol and cardiovascular risk: an issue close to the heart. Lancet 367:627-629

46. Williams B, Lacy PS, Thom SM, Cruickshank K, Stanton A, Collier D, Hughes AD, Thurston H, O'Rourke M (2006) Differential impact of blood pressure-lowering drugs on central aortic pressure and clinical outcomes: principal results of the Conduit Artery Function Evaluation (CAFE) study. Circulation 113:1213-1225

47. Willich SN, Levy D, Rocco MB, Tofler GH, Stone PH, Muller JE (1987) Circadian variation in the incidence of sudden cardiac death in the Framingham Heart Study population. Am J Cardiol 60:801-806 